\title{
Emergence of Salmonella epidemics: The problems related to Salmonella enterica serotype Enteritidis and multiple antibiotic resistance in other major serotypes
}

\author{
Philippe VelgE ${ }^{\mathrm{a} *}$, Axel CloecKAerT ${ }^{\mathrm{b}}$, Paul BARROW ${ }^{\mathrm{c}}$ \\ a Institut National de Recherche Agronomique, Centre de Tours-Nouzilly, \\ UR 918, Pathologie Infectieuse et Immunologie, 37380 Nouzilly, France \\ b Institut National de Recherche Agronomique, Centre de Tours-Nouzilly, \\ UR 086, BioAgresseurs, Santé, Environnement, 37380 Nouzilly, France \\ ${ }^{\mathrm{c}}$ Institute for Animal Health, Compton Lab, Newbury RG20 7NN, Berks, United Kingdom
}

(Received 9 June 2004; accepted 2 November 2004)

\begin{abstract}
Two major changes in the epidemiology of salmonellosis occurred in the second half of the 20th century: the emergence of food-borne human infections caused by $S$. Enteritidis and by multiple-antibiotic resistant strains of Salmonella. This review updates information on the $S$. Enteritidis pandemic and focuses on the emergence of Salmonella, carrying the SGI1 antibiotic resistance gene cluster, resistant to extended-spectrum cephalosporins, or resistant to fluoroquinolones. The factors responsible for the emergence of these Salmonella strains could be either of human origin or related to bacterial genome evolution. However, our increasing understanding of the molecular fluidity of the genome shows that any attempt to counteract bacteria results in further bacterial evolution or adaptation of other bacteria to take place in the new free ecological niche. In these conditions, we can ask who is faster: humans who want to eliminate bacterial pathogens or bacteria that continuously evolve to gain new niches.
\end{abstract}

Salmonella / emergence / antibiotic resistance / virulence / genome evolution

Table of contents

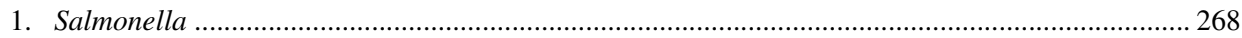

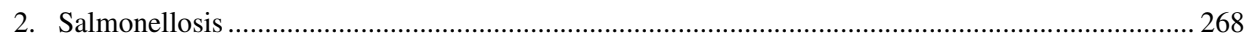

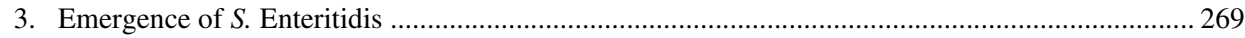

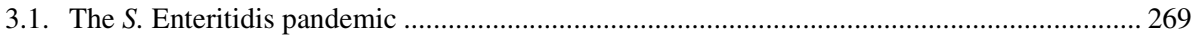

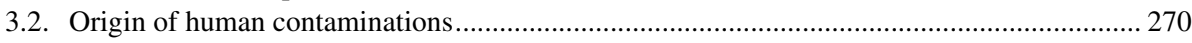

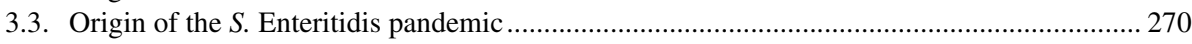

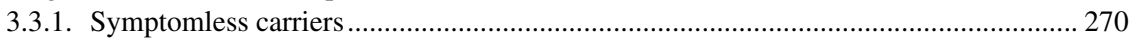

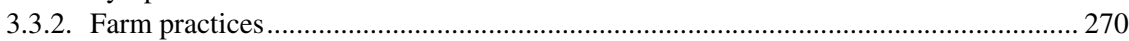

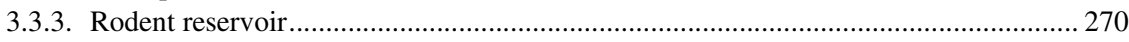

3.3.4. Acquisition of new virulence properties ............................................................. 271

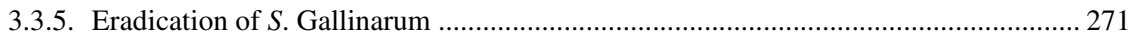

\footnotetext{
* Corresponding author: velge@tours.inra.fr
} 
3.4. Fluctuation or fall of the $S$. Enteritidis pandemic? .........................................................272

4. Source of emergence: microbial genome evolution ....................................................................2272

5. Emergence of multiple-antibiotic resistance in $S$. enterica serotypes ............................................273

5.1. Emergence of multiple-antibiotic resistant $S$. Typhimurium DT104 ..................................274

5.1.1. The Salmonella genomic island 1 (SGI1) ......................................................274

5.1.2. Origin of the SGI1 antibiotic resistance gene cluster. .........................................276

5.2. Emergence of variant SGI1 antibiotic resistance gene clusters in other serotypes.................277

5.3. Re-emergence of high-level fluoroquinolone resistance ...................................................278

5.4. Emergence of resistance to extended spectrum cephalosporins ........................................279

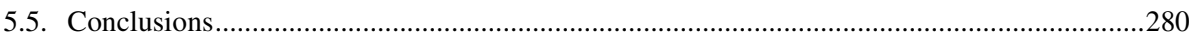

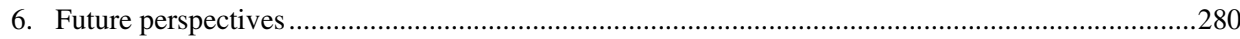

\section{SALMONELLA}

The genus Salmonella is a typical member of the family Enterobacteriaceae and consists of Gram-negative, nonspore-forming bacilli. Bacteria constituting the genus contain three different types of antigens. The agglutinating properties of the somatic $\mathrm{O}$, flagellar $\mathrm{H}$ and capsular $\mathrm{Vi}$ antigens are used to differentiate among more than 2500 serologically distinct types of Salmonella [122]. Each year, new serotypes are listed in annual updates of the Kauffmann-White scheme [122]. The genus Salmonella consists of only two species, S. bongori and S. enterica, whith the latter being divided into six subspecies: entericae, salamae, arizonae, diarizonae, houtenae, indica. Within S. enterica subsp. I (S. enterica subsp. entericae), the most common O-antigen serogroups are A, B, C1, C2, D and E. Strains within these serogroups cause approximately $99 \%$ of Salmonella infections in humans and warm-blooded animals [143]. Serotypes in other subspecies are usually isolated from cold-blooded animals and the environment but rarely from humans [78, 143]. Salmonella nomenclature is complex, and scientists use different systems to refer to this genus. The nomenclature used in this review is based on names for serotypes in subspecies I. For example, Salmonella enterica subsp. entericae serotype Enteritidis, is shortened to Salmonella serotype (ser.) Enteritidis or Salmonella Enteritidis [23]. Salmonella serotypes can be further subdivided by using biotyping and phage typing. A bio- type is the biochemical variation between two microbes of the same serotype, whereas the phage type reflects differences between two organisms with the same serotype but different susceptibilities to a lytic bacteriophage $[146,148]$. Phage typing has played a central role in epidemiological studies in $S$. Typhimurium and in understanding the evolution of the $S$. Enteritidis pandemic [49].

\section{SALMONELLOSIS}

The degree of host adaptation varies between Salmonella serotypes and affects the pathogenicity for man and animals. Serotypes adapted to man, such as $S$. Typhi and $S$. Paratyphi, usually cause severe diseases in humans as a septicaemic typhoidic syndrome (enteric fever). These serotypes are not usually pathogenic to animals. Serotypes that are highly adapted to animal hosts, such as $S$. Gallinarum (poultry) or $S$. Abortus-ovis (sheep), usually produce very mild symptoms in man. However, $S$. Choleraesuis which has the pig as a primary host, also causes severe systemic illness. In the same way, $S$. Dublin which has a preference for bovines, is primarily responsible for the systemic form of salmonellosis. In young calves this disease causes high mortality, and in adult cattle it results in fever, reduced milk yield, diarrhea, abortion, and occasionally death. Ubiquitous serotypes, such as $S$. Enteritidis or $S$. Typhimurium, which affect both man and animals, generally cause gastrointestinal infections usually less severe 
than enteric fever. However, they also have the capacity to produce typhoid-like infections in mice and in humans or asymptomatic intestinal colonisation in chickens [34].

Salmonella has been recognised as causes of intestinal disease for many years, and methods of control are well established. Despite these, Salmonella remains the primary cause of reported food poisoning worldwide and recent years have seen massive outbreaks. $S$. Typhi and other humanadapted Salmonella are rarely transmitted by food compared to ubiquitous serotypes. For this reason, the human adapted serotypes are often excluded from discussion of Salmonella infection. Currently, approximately 30000 to 40000 human cases per year of non-typhoidal salmonellosis are reported to Centers for Disease Control and Prevention (CDC) [95]. Taking into account the degree of under-reporting, the CDC estimates the annual number of cases in the United States (USA) to be approximately 1.4 million [95]. In the European Union (EU), the number of human cases reported to Enternet was greater than 100000 in 1997 [106]. In recent years, the incidence of salmonellosis has shown a sustained decrease across the EU ( 73000 cases in 2001) and also in the USA since 1996 [5, 106].

The epidemiology of human disease is dominated, however, by only a few nontyphoidal serotypes. In 2001, approximately $60 \%$ of the human cases reported to the CDC were caused by four serotypes, namely $S$. Typhimurium (22.1\%), S. Enteritidis (17.7\%), $S$. Newport (10.0\%) and S. Heidelberg (5.9\%) [5]. Such dominance is even more pronounced in France, where more than $70 \%$ of human cases were caused by three serotypes: $S$. Enteritidis (33\%), $S$. Typhimurium (32\%), and $S$. Hadar (6\%) [19].

Two major changes in the epidemiology of non-typhoidal salmonellosis in the EU and the USA occurred in the second half of the 20th century: the emergence of foodborne human infections caused by $S$. Enteritidis and by multiple-antibiotic resistant strains of $S$. Typhimurium. A better under- standing of the factors that led to the emergence of these food-borne pathogens may help the design of improved intervention strategies that could reduce the probability that new pathogens could spread in food animal reservoirs [108, 127].

\section{EMERGENCE OF S. ENTERITIDIS}

\subsection{The $S$. Enteritidis pandemic}

By the 1980s, S. Enteritidis O9,12: g,m had emerged as a major concern for food safety in Europe and the Americas. By 1990 in the USA and by 1993 in Europe, it was the most frequently reported Salmonella serotype [5, 19, 33, 127].

In the USA, $S$. Enteritidis steadily increased in frequency from being the sixth most common serotype in 1963 to becoming the most frequently reported serotype in 1990. Epidemics in the USA are marked by regional differences. S. Enteritidis emerged in 1979 in New England and the Mid-Atlantic regions. In the early 1990s, while $S$. Enteritidis rates of infection in the Northeast began to decline, the $S$. Enteritidis epidemic expanded to the Pacific region. Nationwide, the number of $S$. Enteritidis isolates reported to the CDC peaked at 3.8 per 100000 population in 1995. Although the number of $S$. Enteritidis isolates reported to the CDC had significantly declined to 1.9 by 1999 , this rate did not decline further through 2001 and even increased in the south-eastern regions [4].

In England and Wales, there were 200 reported human cases in 1966, which rose to 10000 in 1981 , and peaked at 33000 in 1997 (more than $70 \%$ of human cases of salmonellosis) [33, 149]. Despite a subsequent decline in its incidence, $S$. Enteritidis continues to be the most frequently isolated Salmonella serotype in the United Kingdom with 16465 cases in 2001 [33].

In France, $S$. Enteritidis has become the most common isolated serotype in 1993. The incidence of $S$. Enteritidis human isolates 
increased exponentially from 1987 to peak at 6500 in 1994 and 1997 and subsequently declined to 4500 cases in 1999 [19]. Similar trends have also been reported from other countries in South America and Europe [33, 127].

\subsection{Origin of human contaminations}

Investigation of outbreaks and sporadic cases has repeatedly indicated that, when a food vehicle is identified, the most common sources of $S$. Enteritidis infection are poultry and poultry derivatives, particularly, in the case of outbreaks, undercooked and raw eggs $[35,41,65,74]$. Although contamination of egg products with other Salmonella serotypes is a long-standing problem, that has been attributed either to the use of damaged eggs or to contamination at or after breaking, the situation with $S$. Enteritidis is different. Egg shells can be contaminated with Salmonella as a result of intestinal carriage but the contents can also become infected by the transovarian route $[79,146]$.

\subsection{Origin of the $S$. Enteritidis pandemic}

\subsubsection{Symptomless carriers}

The factors responsible for the epidemic spread of $S$. Enteritidis are still unclear. One of the factors that may have been important for the epidemiological spread of this pathogen is the difficulty to detect the contamination of the chicken. It is particularly known that $S$. Enteritidis causes symptomless intestinal infections in a wide range of species, especially birds [45, 135]. Acute outbreaks of clinical disease with high mortality may nevertheless occur in chicks younger than two weeks of age [88]. Symptomless carriage may facilitate the spread of infection within a flock by environmental contamination of their intestinal contents $[46,53]$. Another difficulty is that the presence of $S$. Enteritidis within contaminated eggs is difficult to detect until the bacteria exceed log 9.0 per egg [79].

\subsubsection{Farm practices}

The modernisation of chicken farms and globalisation of bird breeding trade have also played a role in the spread of $S$. Enteritidis. For example, the most prevalent molt strategy in the USA is feed removal until hens lose a specific weight. However, hens molted in this way were found to be 100 - to 1000 -fold more susceptible to infection by $S$. Enteritidis and excreted significantly higher numbers in their faeces [75]. Several authors reported that the major risk factors were related to disinfection, hygiene barriers and feedmill [37, 69]. Epidemiological investigations in The Netherlands indicated that laying flocks become infected mainly directly from the farm environment and the contribution from the vertical infection route (from infected breeding flocks to progeny) is small [144]. In contrast, Ward et al. have suggested that the spread of the $S$. Enteritidis epidemic in the United Kingdom was related to the introduction of poultry breeding lines infected with phage type 4 in the UK in the early 1980s [150].

\subsubsection{Rodent reservoir}

However, these data have no bearing on the origins of the epidemic. Several authors have suggested that $S$. Enteritidis was introduced into poultry flocks by rodents where it is endemic since in the distant past it was used as a rodenticide [51,71]. $S$. Enteritidis was first used to control rodent populations during the Yersinia pestis outbreak in San Francisco in 1895 and then occasionally in Europe until 1960 [127]. There is a correlation between the presence of Salmonella in mice and the contamination of poultry. Moreover, some recent reports have shown that several wildlife species, especially rodents, are involved in the maintenance of $S$. Enteritidis infection on farms $[38,52$, 86]. It is unlikely, however, that there is a causal link between the use of $S$. Enteritidis 
as rodenticide and the human cases reported since 1960 [61, 129]. The use of the phage typing system has indeed shown that the majority of human cases in Europe were caused by PT 8 before 1980 and by PT4 afterwards. In contrast, $S$. Enteritidis isolates from rodenticides used in the UK in the 1940s belong to PT6 [51] and those found in rodents in 1993 belong to PT23 [61]. Nevertheless, Threlfall et al. point out the fact that the acquisition of the IncX plasmid converts strains of PT4 to PT6a found in rodents [140].

\subsubsection{Acquisition of new virulence properties}

The dramatic increase of $S$. Enteritidis PT4 infection in Western Europe since 1980 suggested that it might have recently acquired new virulence genes. This hypothesis is strengthened by fingerprinting observations showing a highly clonal structure of the strains investigated, and suggesting that the epidemic in the UK is the result of the efficient spread of just one clone rather than the alteration of conditions which might have favoured the dissemination of several clones or serotypes simultaneously [68]. This clone may have acquired genetic changes, which might have facilitated the spread of PT4. Besides several reports showing that the PT4 spread from experimentally infected chicks to uninoculated chicks occurs at a lower frequency than that of PT8 and PT13, most reports have shown that some PT4 strains tend to be more virulent than other phage types $[8,54,73]$. Additionally, Poppe et al. reported that in orally inoculated oneday old chickens and in laying hens, the clinical UK $S$. Enteritidis PT4 strain was more virulent than the Canadian PT4 strain, which was not epidemic in Canada at this date [123].

Investigations in the laboratory and on farms, have failed to reveal any unique properties of $S$. Enteritidis PT4. It has been possible, however, to observe that $S$. Enteritidis emerged because it was associated with a new food source, namely chicken eggs.
We can thus hypothesise that $S$. Enteritidis acquired new genes to increase the efficiency of its infection of the reproductive tract. Interestingly, recent results have demonstrated that repeated passages through the reproductive tract of chickens increased the ability of an $S$. Enteritidis strain PT13a to induce internal contamination of eggs in an oral infection model, as opposed to serial passages through the liver and spleen that did not significantly affect the ability of this strain to cause egg contamination [55]. One gene, which might be related to adaptation to egg contamination, is yafD, whose overexpression conferred upon $S$. Typhimurium an enhanced resistance to egg albumen, while disruption of this gene in $S$. Enteritidis rendered the organism more susceptible to egg albumen [91].

\subsubsection{Eradication of S. Gallinarum}

The analysis of $S$. Enteritidis isolates worldwide reveals the existence of two major evolutionary lineages: one found in Western Europe, Japan and South America (PT4) and another found in the USA, Canada, and the Slovak Republic (PT8 and PT13a) [42, $72,92,104,124]$. These geographical differences render the pandemic difficult to completely explain as the spread of a single clone of the bacterium. It has recently been proposed that the eradication of $S$. Gallinarum opened an ecological niche, which allowed the introduction of $S$. Enteritidis into poultry flocks [12]. Because the immunodominant epitope of the lipopolysaccharide of $S$. Gallinarum and $S$. Enteritidis is the O9-antigen, mathematical models predict that the coexistence of these two serotypes would prompt competition where the more transmissible bacterium will eliminate the other from the host population [62], either as a result of adaptive immunity, or as a result of microbial competition, which is also partially clonal at the level of the serotype [14]. S. Gallinarum may have generated immunity at the flock level against the O9-serotype, thereby excluding $S$. Enteritidis from poultry flocks [126]. According 
to this hypothesis, if $S$. Gallinarum had been eradicated from poultry by vaccination rather than by the killing of infected animals, the resulting flock immunity against the O9serotype might have prevented the emergence of $S$. Enteritidis [82]. However, in this hypothesis, vaccination had to continue even after eradication of $S$. Gallinarum to continue to prevent introduction of $S$. Enteritidis.

\subsection{Fluctuation or fall of the $S$. Enteritidis pandemic?}

Recent data show a sustained decrease in the number of human cases since 1996 in the USA [5], 1997 in the UK [33] and 1999 in France [19]. In England and Wales, the rate of $S$. Enteritidis infection fell by over $50 \%$ between 1997 and 2000 which corresponded to the period of introduction of new live vaccines which were easier to administer to hens in contrast to the initial vaccines based on formalin-killed bacteria [150]. However, vaccination cannot be the sole cause of this decline, because $S$. Enteritidis infections decreased in several countries that do not vaccinate hens. In addition, the proportion of $S$. Typhimurium infections has also declined in a number of countries $[5,19]$. This decline might thus also be attributed to the implementation of other preventive measures, including on-farm control programmes, improved hygiene and consumer and food-worker education [145]. One important control is the microbiologic testing of hen houses for the presence of $S$. Enteritidis. If the bacterium is found on a farm during routine environmental testing, eggs may be diverted to pasteurisation. The evidence suggests that proper implementation and overlook of farm-based control programmes can result in a significant reduction of $S$. Enteritidis infections among flocks in poultry houses [152]. However, some reports tend to show that the pandemic has become stabilised rather than showing a real decline. For example, this decline did not occur in Spain, where an increase was recorded [93].
In addition, since 2001 a change in phage type distribution in $S$. Enteritidis infections among European travellers returning from some countries in southern Europe was observed, and a previously rare phage type (PT14b) became one of the most commonly diagnosed in England and Sweden [105, 107]. In the USA, although the number of culture-confirmed $S$. Enteritidis infections reported to the CDC declined in 1999, the number has not decreased since this date and some regions have seen increases again with the appearance of PT4 infections [4, 33]. An explanation for the current variations in Salmonella infections could be related to the ubiquity of $S$. Enteritidis and $S$. Typhimurium in poultry flocks leading to flock immunity that could have led to their decline [33]. However, it is possible that, as a serotype becomes less prevalent, the number of immune individuals decreases, which that could itself lead again to an increase in prevalence.

\section{SOURCE OF EMERGENCE: MICROBIAL GENOME EVOLUTION}

Over the past few years, an increasing number of microbial genomes have been sequenced and compared, allowing for the estimation of the frequencies of mutations influencing their genomic structures [118, 136]. By quantifying these differences, it has been observed that considerable genomic variability is found both in Escherichia coli and Salmonella enterica $[48,109]$. The ratio of rearrangements to substitutions is over 2000-fold higher in their genomes than that which occurs in Buchnera aphidicola the obligate bacterial endosymbiont of aphids [98].

An important source of genome evolution is the site-specific recombination mechanism required for the processing of the replicated linear chromosome ends and involved in intra-genomic recombination [83]. Intergenomic exchange involving homologous recombination probably further increases 
the variability seen in these systems. Diversity is also generated by mutagenesis, which may be related to the inactivation of the mismatch pathway normally involved in eliminating errors escaping the replication proofreading process [56]. This mechanism plays a less prominent role in clonal diversity than recombination [132]. However, it is difficult to account for the ability of bacteria to exploit new niches through these genetic mechanisms, and there is growing evidence that lateral gene transfer has played a crucial role in the evolution of bacterial genomes, altering their ecological and pathogenic characteristics [110]. Genome variability could, indeed, result from the acquisition and/or loss of relatively large regions of the genome carrying groups of genes. Such horizontally transmitted DNA fragments include plasmids, genomic islands, temperate bacteriophages, in addition to transposons and insertion sequences. These mobile elements can undoubtedly provide an advantage for the host cell under specific conditions [110].

Virulence associated genes showing evidence for an origin outside the bacteria in which they are identified and which may be present on such a mobile element, are referred to as a pathogenicity island (PAI). Recent studies have shown that acquired PAI are major contributors to the virulence nature of many pathogenic bacteria $[60,63]$, including Salmonella where they are referred to as Salmonella Pathogenicity Islands (SPI). These chromosomally encoded regions typically contain large clusters of virulence genes and have the potential to increase the virulence of a micro-organism or even to transform a benign organism into a pathogen [100]. Until now, 12 SPI have been described. Some of them are conserved throughout the genus Salmonella, while others are specific for certain serotypes like SPI-8 for $S$. Typhi or for certain subspecies like SPI-6, 9, 10 and SGI-1 for subspecies I serotypes [70]. PAI are often associated with tRNA loci, which may represent target sites for the chromosomal integration of these elements [63]. The sequences flanking PAI also frequently contain short direct repeats reminiscent of those generated upon the integration of mobile elements. Open reading frames within PAI sometimes display sequence similarity to bacteriophage integrases, suggesting that lysogenisation by bacteriophages encoding virulence determinants can result in the conversion of a strain into a pathogenic variant. For example, horizontal transfer of the sopE1 gene by lysogenic conversion with the SopEphi phage increased the enteropathogenicity of $S$. Typhimurium in the bovine ligated ileal loop model, suggesting that the horizontal transfer of type III dependent effector proteins may have contributed to the emergence of epidemic cattle-associated $S$. Typhimurium clones $[18,156]$. Another important source of diversity is provided by the acquisition of integrons. They may be part of mobile elements such as transposons, plasmids, and chromosomal genomic islands. Integrons usually carry one or more antibiotic resistance gene cassettes and can sometimes be complex such as the class 1 integron found in SGI1 [21]. In such a case, it looks more like an antibiotic resistance gene cluster and to date SGI1 variants have been identified carrying up to six antibiotic resistance genes, conferring a multiple-antibiotic resistance profile to antibiotic families of clinical importance such as $\beta$-lactams, aminoglycosides, phenicols, sulfonamides, tetracyclines, and trimethoprim [21, 22]. In addition, the structures carrying these various antibiotic resistance genes may undergo recombinational, gene replacement and gene capture events, which can lead to a wide variety of antibiotic resistance gene clusters [22, 43, 44].

\section{EMERGENCE \\ OF MULTIPLE-ANTIBIOTIC RESISTANCE IN S. ENTERICA SEROTYPES}

An inevitable side effect of antibiotic use, which is associated to the adaptability of bacteria and microbial genome evolution, is the emergence and dissemination of resistant bacteria, not only in pathogenic bacteria 
but also in the endogenous flora of man and animals. Resistant commensal bacteria of food animals might contaminate, like zoonotic bacteria, meat products, thus reaching the intestinal tract of humans [108]. Resistance genes against antibiotics that are or have only been used in animals, were soon after their introduction not only found in animal bacteria, but also in the commensal flora of humans, in zoonotic pathogens like Salmonella, and in strictly human pathogens, like Shigella [9]. There is evidence, indeed that resistance determinants can transfer between unrelated bacteria such as Bacteroides on the one hand and Salmonella and Escherichia on the other [108]. Therefore, not only does the clonal spread of resistant strains occur, but there is also a transfer of resistance genes between human and animal bacteria [108].

Resistance can be caused by a large number of mechanisms, involving decreased antibiotic accumulation, physical modification or destruction of the antibiotics, and alteration of the enzyme target of antibiotic action. Recently, a mechanism of resistance involving the active efflux of antibiotics by multidrug efflux pumps was also elucidated $[84,121,131]$.

\subsection{Emergence of multiple-antibiotic resistant $S$. Typhimurium DT104}

Multiple-antibiotic resistant $S$. Typhimurium definitive phage type (DT) 104 emerged during the last decade as a global health problem because of its involvement in diseases in animals and humans $[31,125,141]$. Multiple-antibiotic resistant strains of this phage type were first detected in the United Kingdom in cattle and humans in the late 1980s, but have since become common in other animal species such as poultry, pigs and sheep. Human infections with multipleantibiotic resistant DT104 isolates have been associated with the consumption of chicken, beef, pork, sausages and meat paste [147]. The $S$. Typhimurium DT104 epidemic is now worldwide with a considerable number of outbreaks since 1996 in the USA and Canada [16, 59, 125].

These multiple-antibiotic resistant strains are generally resistant to ampicillin (Ap), chloramphenicol $(\mathrm{Cm}) /$ florfenicol (Ff), streptomycin (Sm)/spectinomycin (Sp), sulfonamides (Su), and tetracyclines (Tc). Genes associated with these resistance properties have been found to be chromosomally encoded [138]. Additional resistance to trimethoprim (Tm), occasionally seen among $S$. Typhimurium DT104 strains, may be encoded by a non-conjugative but mobilisable plasmid of approximately 4.6 MDa which also encodes resistance to $\mathrm{Su}$ [139]. Transferable apramycin resistance has also been described in some DT104 strains [90].

\subsubsection{The Salmonella genomic island 1 (SGII)}

The ApCmFfStSpSuTc multiple-antibiotic resistance profile of $S$. Typhimurium DT104 is conferred by an antibiotic resistance gene cluster carried by a chromosomal genomic island called Salmonella genomic island 1 (SGI1) [20, 21]. The $43 \mathrm{~kb}$-size SGI1 is located between the $t h d F$ and int 2 genes of the chromosome of $S$. Typhimurium DT104 and is flanked by an imperfect 18-bp direct repeat (Fig. 1). The $t h d F$ gene codes for a thiophene-and furan-oxidation protein. The int 2 gene, a prophage $\mathrm{CP}-4$ like integrase gene, is part of a retron sequence which has to date been reported only in strains of serotype Typhimurium [20]. The antibiotic resistance gene cluster is located near the 3' end of SGI1 and constitutes a complex class 1 integron belonging to the In 4 group. Class 1 integrons contain a 5' conserved segment (5'-CS) which consists of the intIl gene encoding the site-specific integrase and the associated attIl site, the primary site of recombination, and a 3'-conserved segment (3'-CS) of variable length but generally consisting of qacEl encoding low level resistance to some antiseptics, the sull gene encoding sulfonamide resistance, and orf5, a gene of unknown function [50]. 
SGI1 (S. Typhimurium DT104, S. Agona, $S$. Paratyphi B)

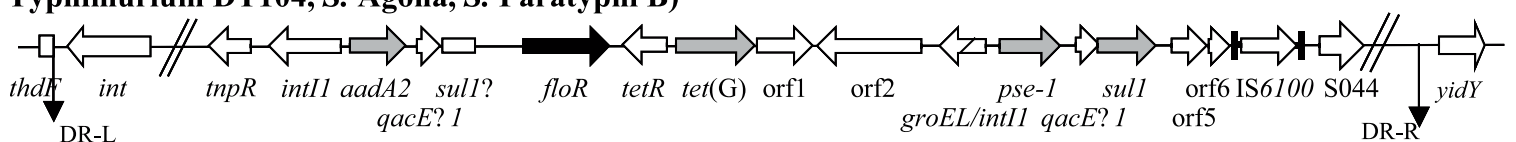

\section{SGI1-A (S. Agona)}

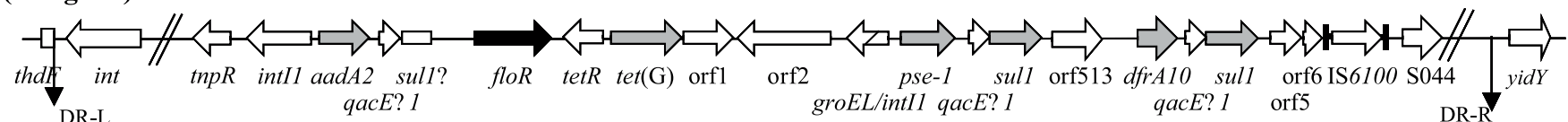

\section{SGI1-F (S. Albany)}

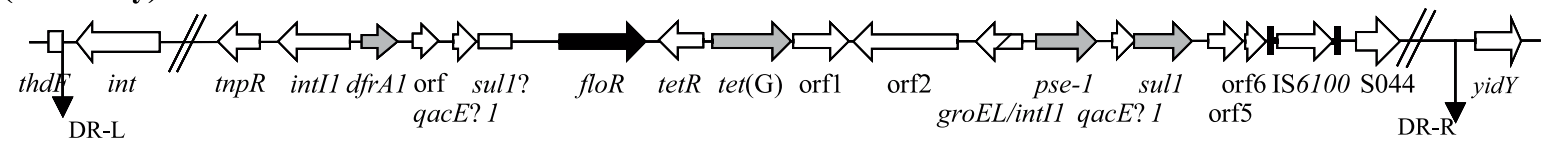

\section{SGI1-H (S. Newport)}

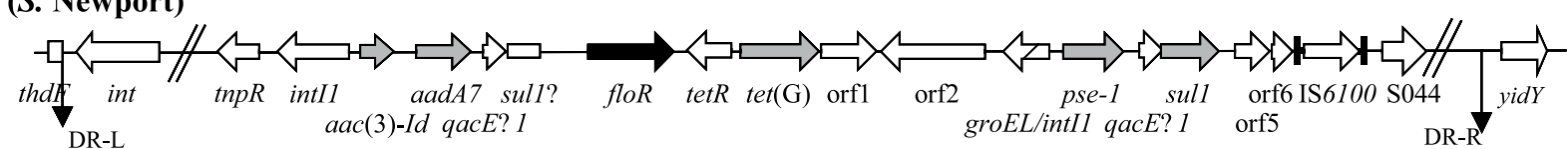

Figure 1. Genetic organization of various antibiotic resistance gene clusters of Salmonella Genomic Island 1 (SGI1) in different Salmonella enterica serotypes. SGI1 and variants (SGI1-A, SGI1-F, SGI1-H) are always located between the thdF and $y i d Y$ chromosomal genes. DR-L and DR-R are the left and right repeats, respectively, bracketing SGI1. The first SGI1 gene int codes for a putative integrase probably involved in site-directed integration of SGI1 at the 3' end of thdF. The various antibiotic resistance gene clusters mediate resistance to ampicillin (pse-1), cloramphenicol and florfenicol $(f l o R)$, gentamicin (aac(3)-Id), streptomycin and spectinomycin (aadA2, aadA7), sulfonamides (sull), tetracyclines (tet(G)), and trimetoprim (dfrA1, dfrA10). 
One or more gene cassettes consisting of the coding region(s) and the downstream 59base element (59-be), which is responsible for recognition and mobilisation of cassettes, are found between the 5' -CS and 3'CS [50]. Transposon Tn402 is a mobile class 1 integron that contains the 5'-CS and a transposition module (tni region) consisting of four genes required for transposition [25]. In addition, $\mathrm{Tn} 402$ is bound by inverted repeats of $25 \mathrm{bp}, \mathrm{IRi}$ at the integrase end, and IRt at the tni end. Several class 1 integrons appear to have originated from a Tn402-like ancestor by incorporation of the common part of the 3'-CS including qacE1, sull, and orf5. Most of these integrons, though still bound by IRi and IRt, have lost part or all of the tni module and are deemed defective transposon derivatives [25]. The In 4 group has a 3'-CS that includes a copy of IS6100 but no transposition genes and most members are bound by IRi and IRt $[114,115]$. The antibiotic resistance gene cluster of SGI1 is bound by IRi and IRt and thus, can be considered a complex In4-type integron [22]. Furthermore, the multipledrug resistance region is surrounded by 5-bp direct repeats, strongly suggesting that it was integrated through transposition [22, 114]. Interestingly, in SGI1 there is a duplication of a part of the 5'-CS, leading to a second attIl site followed by a gene cassette. At the first attIl site, the cassette carries the aadA2 gene, which confers resistance to $\mathrm{Sm}$ and $\mathrm{Sp}$, and a 3'-CS with a truncated sull (sull) gene. At the second attIl site, the cassette contains the $\beta$-lactamase gene $b l a_{\mathrm{PSE}-1}$ conferring resistance to Ap and a 3'-CS with a complete sull gene conferring resistance to $\mathrm{Su}$. Flanked by the two cassettes are, first the floR gene, which confers cross-resistance to $\mathrm{Cm}$ and $\mathrm{Ff}$, and second the tetracycline-resistance genes tetR and $\operatorname{tet}(\mathrm{G})[6,17]$. According to the deduced amino acid sequence homologies and the topology of the deduced protein, the floR and tet $(\mathrm{G})$ genes encode efflux pumps belonging to the 12-transmembrane segment (TMS) family export proteins of the major facilitator superfamily (MFS) reviewed by Paulsen et al. [117]. Variant antibiotic resistance gene clusters of SGI1 have recently been described in $S$. Typhimurium DT104 [22]. In some cases, there is only one 5' -CS and hence, a single gene cassette, either aadA2

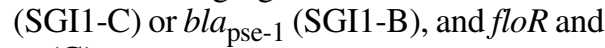
tet $(\mathrm{G})$ are not present.

\subsubsection{Origin of the SGI1 antibiotic resistance gene cluster}

Several authors have speculated on the origin of the $S$. Typhimurium DT104 antibiotic resistance gene cluster and consecutive spread of multiple-antibiotic resistant $S$. Typhimurium DT104 strains [3, 39, 40]. The use of antimicrobial agents in agriculture, particularly in intensive calf rearing in the 1970-1980s, might have contributed to the emergence of multiple-antibiotic resistant $S$. Typhimurium DT104 strains. The genes included in the antibiotic resistance gene cluster of $S$. Typhimurium DT104 strains confer resistances to drugs belonging to four out of the five classes of antimicrobials most frequently used in veterinary medicine (tetracyclines, $\beta$-lactams, aminoglycosides and sulfonamides) and co-selection of the entire cluster may thus result from the use of any of these drugs. While some genes in the cluster, such as aadA2, bla $a_{\mathrm{PSE}-1}$, or sulI, are widely distributed among the Enterobacteriaceae, the remaining two genes, floR and $\operatorname{tet}(\mathrm{G})$, are most probably not of enterobacterial origin.

$\mathrm{Ff}$ is a veterinary antimicrobial agent that has been used in aquaculture in Asia since the early 1980s. A floR homolog was first identified on a plasmid in Pasteurella piscicida recently renamed Photobacterium damselae, a fish pathogen [80]. In addition, the class $\mathrm{G}$ tetracycline resistance gene associated with the floR gene in the $S$. Typhimurium DT104 antibiotic resistance gene cluster was first identified in Vibrio anguillarum, also a fish pathogen [157]. The $\operatorname{tet}(\mathrm{G})$ gene has also been detected on plasmids of Photobacterium damselae [81]. Based on these data, and on the fact that the floR and $\operatorname{tet}(\mathrm{G})$ 
genes in $S$. Typhimurium DT104 have a similar $\mathrm{G}+\mathrm{C}$ content (58\%), Angulo et al. [3] suggested that the resistance determinants of multiple-antibiotic resistant $S$. Typhimurium DT104 strains have the same origin and may have emerged amongst bacteria in aquaculture and subsequently been horizontally transferred to $S$. Typhimurium DT104. However, Davis et al. [40] suggested an origin in Pseudomonas sp. Indeed, tet $(\mathrm{G})$ also occurs in bacteria of this genus [130], and similarly floR is closely related to the $P$. aeruginosa chloramphenicol-resistance gene $\mathrm{cmlA}$ [6, 24]. Moreover, the $b l a_{\mathrm{PSE}-1}$-encoded $\beta$-lactamase is a common feature of hospital $P$. aeruginosa isolates [120]. Thus, the hypothesis that $S$. Typhimurium DT104 acquired resistance genes horizontally from nosocomial pseudomonads might also be worth considering. The association of floR with the tet $R$ and $\operatorname{tet}(\mathrm{G})$ genes has nevertheless not yet been described in bacteria other than of the $S$. enterica serotypes. One might expect to find it in $E$. coli isolates also, if this was a general event.

Using pulsed-field gel electrophoresis (PFGE), several studies have concluded that multiple-antibiotic resistant $S$. Typhimurium DT104 has probably been spread clonally in European countries and the United States [27, 85, 141]. Evidence to the contrary has been found by others, including, Markogiannakis et al. [94] who also using PFGE, have shown that six distinct clones are present among Greek multiple-antibiotic resistant $S$. Typhimurium DT104 isolates. In a recent review, Tauxe also stated that multiple-antibiotic resistant $S$. Typhimurium DT104 represents a cluster of strains with related lysotyping patterns, including DT104, DT104a, DT104b, and U302 and thus, the epidemic would be more accurately described as being due to a cluster of related strains [137]. It is also interesting to note that strains showing the same macrorestriction pattern still exhibit genetic diversity if other analysis methods are used, such as infrequent restriction site PCR (IRSPCR) and amplified fragment length polymorphism (AFLP) [21]. The occurrence of
SGI1 in several clones would suggest a potential for horizontal transfer of this genomic island.

\subsection{Emergence of variant SGI1 antibiotic resistance gene clusters in other serotypes}

Horizontal transfer of SGI1 has been supported by its discovery in other $S$. enterica serotypes, namely $S$. Agona, $S$. Paratyphi B, $S$. Albany, and $S$. Newport [22, 43, 44, 97]. In these serotypes, SGI1 has the same chromosomal location as in $S$. Typhimurium DT104, i.e. it is inserted at the 3' end of the thdF gene. However, all serotypes were shown to lack the retron sequence found so far only in $S$. Typhimurium. Interestingly new SGI1 variants were identified in $S$. Agona, $S$. Albany, and $S$. Newport (Fig. 1). These clusters of antibiotic resistance genes were likely generated, according to sequence analysis, as a result of chromosomal recombination events or by antibiotic resistance gene cassette replacement at one of the attII sites.

In $S$. Agona strains, three SGI1 variant antibiotic resistance gene clusters, SGI1-A (complex class 1 integron containing the entire antibiotic resistance gene cluster), SGI1-D (class 1 integron containing only the aadA2 gene cassette), and SGI1-G (class 1 integron containing only the bla $a_{\mathrm{PSE}-1}$ gene cassette), the 3'-CS (designated 3'-CS1) is followed by a $2154-b p$ common region (CR) originally described in In6 and In7 [112, 133]. There is a unique region adjacent to the $\mathrm{CR}$ that includes $d f r A 10$ (Tm resistance), as in In7 [112]. Following this unique region is a second partial copy of the 3'-CS, designated 3'-CS2. The CR itself contains a gene, designated orf513, whose deduced product is thought to be a putative transposase [22], which is postulated to interact with the 27-bp boundary sequence and mobilise antibiotic resistance genes [113].

The variant SGI1-F from $S$. Albany represented the first example of replacement of one of the attIl sites of the gene cassette [43]. In this isolate, the $\mathrm{Sm} / \mathrm{Sp}$ resistance 
aadA2 gene cassette at the first attII site was replaced by a $d f r A l$ gene cassette and an open reading frame of unknown function. The $d f r A l$ and orf gene cassettes may have been introduced by homologous recombination with a class 1 integron containing the same array of gene cassettes from another bacterium [116]. Another possibility is the exchange between aadA2 and the two gene cassettes which would imply excision, mediated by the integron-encoded integrase, of aadA2 and its replacement by the other gene cassettes [64]. The array of gene cassettes found at the first attIl site of the $S$. Albany strain was interestingly the same as those recently reported in integrons from Vibrio cholerae isolated in Thailand and India [36, 142].

The variant SGI1-H from $S$. Newport strains isolated from French patients with gastroenteritis represented the second example where gene cassette replacement took place in one of its attII sites [44]. In these strains, the $\mathrm{Sm} / \mathrm{Sp}$ resistance gene cassette aadA2 inserted at the first attIl site was replaced by two other aminoglycoside resistance gene cassettes. The first cassette contained a new resistance gene encoding an AAC(3)-I aminoglycoside 3- $N$-acetyltransferase which confers resistance to gentamicin $(\mathrm{Gm})$ and sisomicin $(\mathrm{Sc})$. This gene has been named $a a c(3)-I d$. The second cassette harboured the $\mathrm{Sm} / \mathrm{Sp}$ resistance gene aadA7. The array of resistance gene cassettes found in the integron of the $S$. Newport strains were the same as those recently reported in an integron of a Vibrio fluvialis strain (GenBank accession no. AB114632). The natural aquatic environment of pathogenic $V$. fluvialis strains is surface water and it seems likely that antibiotic resistance gene exchange between different bacterial species such as Vibrio and Salmonella probably took place in such aquatic environments. Thus, the SGI1 complex class 1 integron could contribute to the capture in the Salmonella chromosome of a wide diversity of resistance gene cassettes and thus generate diverse antibiotic resistance gene clusters.

\subsection{Re-emergence of high-level fluoroquinolone resistance}

The increasing rates of resistance to traditional anti-Salmonella agents (i.e. Ap, Cm, and trimethoprim-sulfamethoxazole) have turned the treatment of invasive salmonellosis into a clinical dilemma. The emergence of resistance to fluoroquinolones (FQ) among nontyphoid Salmonella is of particular concern, since this class of antimicrobial agents constitutes the drug of choice for treating potentially life-threatening Salmonella infections caused by multiple-antibiotic resistant strains in adults [3].

In Salmonella, quinolone resistance was initially attributed to point mutations in the gyrA gene encoding the A subunit of gyrase, whose complex with DNA is the primary target of quinolones. Resistance mutations of $g y r A$ occur in a region of the gene product between amino acids 67 and 106, termed the quinolone resistance-determining region (QRDR). Amino acid changes at Ser-83 (to Phe, Tyr, or Ala) or at Asp-87 (to Gly, Asn, or Tyr) are the most frequently observed in nalidixic acid (Nal)-resistant strains [30]. Double mutations at both residues 83 and 87 have been identified in clinical isolates of an S. Typhimurium DT204 clone showing high-level resistance to FQ [67]. These strains were mainly isolated between 1991 and 1995 from animals and humans in limited areas in Europe and are highly resistant to ciprofloxacin (Cip) (MIC of $32 \mu \mathrm{g} / \mathrm{mL}$ ). These isolates have in addition an altered gyrB gene encoding the B subunit of gyrase [66]. This consists of a single mutation in the QRDR of $g y r B$ leading to amino acid change Ser464Phe [10]. These isolates also carry a fourth mutation in the QRDR of parC encoding the ParC subunit of topoisomerase IV, which is the secondary target for quinolones. The mutation identified led to amino acid change Ser80Ile [10].

FQ resistance in $S$. Typhimurium has also been attributed to active efflux mechanisms $[57,119]$, and especially to the participation of the AcrAB-TolC efflux system. Indeed, inactivation of the genes coding for either 
the AcrB inner membrane multidrug transporter or the TolC outer membrane channel in $S$. Typhimurium DT204 strains resulted in a 16- to 32-fold reduction of resistance level to several FQ (Cip MIC of $2 \mu \mathrm{g} / \mathrm{mL}$ ) $[10,11]$. Similar results were obtained using the efflux pump inhibitor Phe-Arg- $\beta$-naphthylamide [89]. Thus, using efflux pump inhibitors together with FQ may be promising in combination therapy against highlevel FQ-resistant $S$. Typhimurium. Further reversion of the parC (Ser80Ile) mutation resulted in a further 16- to 32-fold decrease of resistance levels to FQ [11]. High level resistance to FQ in Salmonella is thus essentially explained by the combination of two major resistance mechanisms, i.e. multiple target gene mutations and active efflux mediated by AcrAB-TolC.

Recent reports suggest that high levelFQ resistance is re-emerging in $S$. Typhimurium, $S$. Choleraesuis, and $S$. Schwarzengrund in different parts of the world [28, 76, 102, 111]. Polyclonal re-emergence of high level FQ-resistance is not only reflected by the several serotypes in which this resistance is now encountered, but also by the diversity of the target gene mutations identified: two different double mutations in $g y r A$ [111], one single mutation in $\operatorname{gyr} B$ [28], three different single mutations in parC [102], and for the first time one single mutation in parE [87].

\subsection{Emergence of resistance to extended spectrum cephalosporins}

Extended spectrum (E-S) cephalosporins are the drugs of choice for children because they cannot be treated with FQ. Salmonella and $E$. coli exhibiting resistance to E-S cephalosporins are an emergent problem worldwide. Before 1996, resistance to E-S cephalosporins was rarely reported among Salmonella sp. In 2000, the emergence of domestically acquired infections by E-S cephalosporin-resistant Salmonella carrying a plasmid-mediated CMY-2 AmpC $\beta$-lactamase was reported by the National Antimicrobial Resistance Monitoring Sys- tem (NARMS) in the USA [47]. Molecular and phenotypic analysis of E-S cephalosporin-resistant strains revealed several distinct serotypes and chromosomal DNA patterns, suggesting that this resistance phenotype is present among genetically diverse strains $[47,158]$. It has been recently demonstrated that the bla $a_{\mathrm{CMY}}$ genes in Salmonella reside on different large plasmids [26].

The occurrence of CMY-2-mediated cephalosporin resistance in Salmonella has now been reported in Canada [2], Spain [103], Romania [99], and Taiwan [154]. In 2002, the CDC investigated an outbreak of multiple-antibiotic resistant $S$. Newport infections associated with eating raw or undercooked ground beef [155]. This multidrug resistance phenotype included resistance to $\mathrm{Sm}$, sulfamethoxazole, Tc, Ap, Cm, and decreased susceptibility to E-S cephalosporins. These resistant strains have also been detected in cattle [128]. An increase in prevalence of E-S cephalosporin-resistant strains could be in part related to the use in food animals of ceftiofur, which is an E-S cephalosporin approved for used in veterinary medicine [151]. Since the bla $a_{\mathrm{CMY}}$ genes confer decreased susceptibility to both ceftiofur and ceftriaxone, the use of ceftiofur has the potential to select for Salmonella cross-resistant to ceftriaxone, another E-S cephalosporin used in human medicine. In fact, many plasmids containing $b l a_{\mathrm{CMY}-2}$ genes have been reported to confer additional resistance to aminoglycosides, phenicols, Tc, and Su. Ceftriaxone-resistant Salmonella strains recently isolated from animals in Canada [2] and retail foods in the USA [151] have also been reported to be resistant to florfenicol. The $b l a_{\mathrm{CMY}-2}$-carrying plasmids studied were recently shown to also carry the Ff resistance gene, floR, on a genetic structure previously identified in E. coli plasmids in Europe [32]. These data indicated that the use of different antimicrobial agents, including phenicols, might serve to maintain multiple-antibiotic resistance plasmids on which E-S cephalosporin resistance determinants co-exist with other resistance genes in Salmonella. 
Besides the emergence of multidrug resistance plasmids carrying $b l a_{\mathrm{CMY}-2}$ and floR, other extended-spectrum $\beta$-lactamases have been reported in recent years in Salmonella $[1,7,101]$.

\subsection{Conclusions}

Taken together, antibiotic resistance genes can be propagated by integrons, transposons, mobile genomic islands that can reside in the chromosome, and on plasmids [134]. These mobile elements can collect and recombine numerous resistance gene cassettes in almost any combination as shown for SGI1 [22]. Consequently, treatment with one antimicrobial agent can enrich the population for bacteria resistant not only to that specific agent, but also to all antimicrobial agents whose resistance genes are genetically linked to the agent used (i.e. present as a cluster of genes on the same mobile element). The consequences were not realised in the past by most clinicians, who, in treating with an aminoglycoside, assumed they were selecting for strains resistant to only that antimicrobial agent. This may also explain why, despite periodic cycling of antimicrobials in hospitals, the prevalence of multiple-antibiotic resistant bacteria does not diminish but indeed continues to increase [134].

Antimicrobial resistance can involve not just obvious pathogens but also commensal bacteria, which may act as an enormous reservoir of antimicrobial resistance genes [134]. Thus, antimicrobial use in medicine and agriculture affects the general ecology of bacterial communities, including interactions between bacteria and their environment but also mechanisms by which antimicrobial resistance genes spread and persist. Their use, especially in food animals, can also have adverse effects on human health [9]. One fact that can decrease the impact of antibiotic resistant strains is that for some mechanisms in particular those conferring resistance to FQ in $S$. Typhimurium could have an important fitness cost and could therefore be counter-selected under in vivo conditions [58]. Thus, whereas it is clear that genotypes resistant to an antibiotic are selectively favoured in the presence of this antibiotic, they often have lower growth rates than susceptible genotypes in an antibiotic-free environment. However, one mechanism that can increase the impact of antibiotic resistant strains, involves virulence traits linked to antibiotic resistance gene clusters. For example, besides the antibiotic resistance cluster, SGI1 also carries genes coding for proteins of unknown function that could potentially be involved in the virulence colonisation or infectivity of the multiple-antibiotic resistant $S$. Typhimurium DT104 [21]. This hypothesis might explain the current worldwide epidemic of this pathogen. DT104 was indeed an uncommon phage type before acquiring the multiple-antibiotic resistance phenotype. In this hypothesis, the antibiotic resistance cluster might be regarded as only the small visible tip of an iceberg and spread of multiple-antibiotic resistant $S$. Typhimurium DT104 might thus now occur even without the added selective pressure imposed by the use of antibiotics.

\section{FUTURE PERSPECTIVES}

Effective prevention and control programmes must involve coordinated and simultaneous attacks on the problem from several directions. Vaccination and competitive exclusion are important methods to aid reducing $S$. Enteritidis poultry infection $[37,96,153]$. The prevalence of Salmonella in animals may also be reduced by the genetic selection of animals resistant to disease but also to the asymptomatic carrier state [13, $15,77]$. However, our increasing understanding of the molecular fluidity of the genome suggests that any attempt at extensive biological intervention will result in a further evolution, as the bacterium attempts to overcome the obstacle placed in its ecological path. It has been shown that horizontal gene transfer of foreign DNA coding for novel phenotypes is an important factor in the rapid evolution of bacterial pathogens. In addition, if bacteria in a particular ecologic niche are destroyed, other bacteria 
resulting from adaptation to this new free niche, will replace the original flora. This may have occurred in the replacement of the avian adapted serotype $S$. Gallinarum by zoonotic bacteria, although this has by no means been completely proven and remains in dispute. Similar changes occur in response to the use of antimicrobial agents. The continuous exchange of bacteria between humans and their environment suggests that imposition of any selection on bacteria will result in proliferation of bacterial stains that tend to resist the initial stress. Once acquired, these additional genes will be lost very slowly and in contrast may be transmitted to many other bacteria. In the past, the use and often the misuse of antimicrobials in both humans and animals have given rise to a selection unprecedented in the history of microbial evolution. As a result, humans are facing the emergence of infectious bacteria displaying resistance to many, and in some cases all, effective antimicrobials. The use of antibiotics in livestock, fish and poultry has accelerated the development of antibiotic-resistant bacteria, complicating treatment for both animals and humans. Chemotherapeutic selection may have additional consequences for virulence evolution through the acquisition of linked virulence genes.

Given this information, what might be done to assist combating Salmonella? It is clear that the continuous development of existing surveillance measures (control programmes, traceability of the food chains) and epidemiological expertises is required, both for food-borne pathogens, but also for sentinel organisms, present in the normal flora, and which may represent a huge reservoir of resistance. It is also necessary to understand the mechanisms of evolution to form the foundation for a predictive science of infectious disease enabling us to anticipate the emergence of problems for public health and to evaluate the influence of future changes in animal husbandry with regards to their potential of altering the pathogen population and genome. Genome evolution is indeed one great source of emergence. A second source is the ability of a pathogen to infect multiple hosts, particularly hosts in different taxonomic orders or wildlife [29]. In the case of antimicrobial resistant bacteria, it is of prime importance that all sectors using antibiotics (medicine, veterinary, horticulture) cooperate to minimise the proliferation of resistant bacteria, which may more generally have important consequences for virulence evolution and disease control.

The knowledge of the potential risks, even the perception of the risks, should, however, not mask the real health hazard. We should remember that current food presents much less microbial health hazards than food five decades ago and that the increase in lifespan is partly related to this improvement.

\section{REFERENCES}

[1] AitMhand R., Soukri A., Moustaoui N., Amarouch H., ElMdaghri N., Sirot D., Benbachir M., Plasmid-mediated TEM-3 extended-spectrum beta-lactamase production in Salmonella Typhimurium in Casablanca, J. Antimicrob. Chemother. 49 (2002) 169-172.

[2] Allen K.J., Poppe C., Occurrence and characterization of resistance to extended-spectrum cephalosporins mediated by beta-lactamase CMY-2 in Salmonella isolated from foodproducing animals in Canada, Can. J. Vet. Res. 66 (2002) 137-144.

[3] Angulo F.J., Johnson K.R., Tauxe R.V., Cohen M.L., Origins and consequences of antimicrobial-resistant nontyphoidal Salmonella: implications for the use of fluoroquinolones in food animals, Microb. Drug Resist. 6 (2000) 77-83.

[4] Anonymous, Outbreaks of Salmonella serotype Enteritidis infection associated with eating shell eggs-United States, 1999-2001, Morb. Mortal. Wkly. Rep. 51 (2003) 1149-1152.

[5] Anonymous, Salmonella: annual summary 2001, Centers for Disease Control and Prevention (2003) 1-154.

[6] Arcangioli M.A., Leroy-Setrin S., Martel J.L., Chaslus-Dancla E., A new chloramphenicol and florfenicol resistance gene flanked by two integron structures in Salmonella Typhimurium DT104, FEMS Microbiol. Lett. 174 (1999) 327-332. 
[7] Baraniak A., Sadowy E., Hryniewicz W., Gniadkowski M., Two different extendedspectrum beta-lactamases (ESBLs) in one of the first ESBL-producing Salmonella isolates in Poland, J. Clin. Microbiol. 40 (2002) 10951097.

[8] Barrow P.A., Experimental infection of chickens with Salmonella Enteritidis, Avian Pathol. 120 (1991) 145-153.

[9] Barza M., Potential mechanisms of increased disease in humans from antimicrobial resistance in food animals, Clin. Infect. Dis. 34 Suppl. 3 (2002) S123-S125.

[10] Baucheron S., Imberechts H., Chaslus-Dancla E., Cloeckaert A., The AcrB multidrug transporter plays a major role in high-level fluoroquinolone resistance in Salmonella enterica serovar Typhimurium phage type DT204, Microb. Drug Resist. 8 (2002) 281-289.

[11] Baucheron S., Chaslus-Dancla E., Cloeckaert A., Role of TolC and parC mutation in highlevel fluoroquinolone resistance in Salmonella enterica serotype Typhimurium DT204, J. Antimicrob. Chemother. 53 (2004) 657659.

[12] Baumler A.J., Hargis B.M., Tsolis R.M., Tracing the origins of Salmonella outbreaks, Science 287 (2000) 50-52.

[13] Beaumont C., Protais J., Guillot J.F., Colin P., Proux K., Millet N., Pardon P., Genetic resistance to mortality of day-old chicks and carrier-state of hens after inoculation with Salmonella Enteritidis, Avian Pathol. 28 (1999) 131-135.

[14] Berchieri A., Barrow P.A., Further studies on the inhibition of colonization of the chicken alimentary tract with Salmonella Typhimurium by pre-colonization with an avirulent mutant, Epidemiol. Infect. 104 (1990) 427 441.

[15] Berthelot F., Beaumont C., Mompart F., GirardSantosuosso O., Pardon P., Duchet-Suchaux M., Estimated heritability of the resistance to cecal carrier state of Salmonella Enteritidis in chickens, Poult. Sci. 77 (1998) 797-801.

[16] Besser T.E., Goldoft M., Pritchett L.C., Khakhria R., Hancock D.D., Rice D.H., Gay J.M., Johnson W., Gay C.C., Multiresistant Salmonella Typhimurium DT104 infections of humans and domestic animals in the Pacific Northwest of the United States, Epidemiol. Infect. 124 (2000) 193-200.

[17] Bolton L.F., Kelley L.C., Lee M.D., FedorkaCray P.J., Maurer J.J., Detection of multidrugresistant Salmonella enterica serotype Typhimurium DT104 based on a gene which confers cross-resistance to florfenicol and chlo- ramphenicol, J. Clin. Microbiol. 37 (1999) $1348-1351$

[18] Bossi L., Fuentes J.A., Mora G., FigueroaBossi N., Prophage contribution to bacterial population dynamics, J. Bacteriol. 185 (2003) 6467-6471.

[19] Bouvet P., Grimont P., Données de surveillance 1999 du centre national de référence des Salmonella et Shigella, Bulletin Épidémiologique Hebdomadaire 12 (2001) 1-9.

[20] Boyd D., Peters G.A., Ng L., Mulvey M.R., Partial characterization of a genomic island associated with the multidrug resistance region of Salmonella enterica Typhimurium DT104, FEMS Microbiol. Lett. 189 (2000) 285-291.

[21] Boyd D., Peters G.A., Cloeckaert A., Boumedine K.S., Chaslus-Dancla E., Imberechts H., Mulvey M.R., Complete nucleotide sequence of a 43kilobase genomic island associated with the multidrug resistance region of Salmonella enterica serovar Typhimurium DT104 and its identification in phage type DT120 and serovar Agona, J. Bacteriol. 183 (2001) 57255732.

[22] Boyd D., Cloeckaert A., Chaslus-Dancla E., Mulvey M.R., Characterization of variant $\mathrm{Sal}$ monella genomic island 1 multidrug resistance regions from serovars Typhimurium DT104 and Agona, Antimicrob. Agents Chemother. 46 (2002) 1714-1722.

[23] Brenner F.W., Villar R.G., Angulo F.J., Tauxe R., Swaminathan B., Salmonella Nomenclature, J. Clin. Microbiol. 38 (2000) 2465-2467.

[24] Briggs C.E., Fratamico P.M., Molecular characterization of an antibiotic resistance gene cluster of Salmonella Typhimurium DT104, Antimicrob. Agents Chemother. 43 (1999) 846-849.

[25] Brown H.J., Stokes H.W., Hall R.M., The integrons In0, In2, and In5 are defective transposon derivatives, J. Bacteriol. 178 (1996) 44294437.

[26] Carattoli A., Tosini F., Giles W.P., Rupp M.E., Hinrichs S.H., Angulo F.J., Barrett T.J., Fey P.D., Characterization of plasmids carrying CMY-2 from expanded-spectrum cephalosporin-resistant Salmonella strains isolated in the United States between 1996 and 1998 , Antimicrob. Agents Chemother. 46 (2002) 1269-1272.

[27] Casin I., Breuil J., Brisabois A., Moury F., Grimont F., Collatz E., Multidrug-resistant human and animal Salmonella Typhimurium isolates in France belong predominantly to a DT104 clone with the chromosome- and integron-encoded beta-lactamase PSE-1, J. Infect. Dis. 179 (1999) 1173-1182. 
[28] Casin I., Breuil J., Darchis J.P., Guelpa C., Collatz E., Fluoroquinolone resistance linked to GyrA, GyrB, and ParC mutations in Salmonella enterica Typhimurium isolates in humans, Emerg. Infect. Dis. 9 (2003) 1455-1457.

[29] Cleaveland S., Laurenson M.K., Taylor L.H., Diseases of humans and their domestic mammals: pathogen characteristics, host range and the risk of emergence, Philos. Trans. R. Soc. Lond. B Biol. Sci. 356 (2001) 991-999.

[30] Cloeckaert A., Chaslus-Dancla E., Mechanisms of quinolone resistance in Salmonella, Vet. Res. 32 (2001) 291-300.

[31] Cloeckaert A., Schwarz S., Molecular characterization, spread and evolution of multidrug resistance in Salmonella enterica Typhimurium DT104, Vet. Res. 32 (2001) 301-310.

[32] Cloeckaert A., Baucheron S., Flaujac G., Schwarz S., Kehrenberg C., Martel J.L., ChaslusDancla E., Plasmid-mediated florfenicol resistance encoded by the floR gene in Escherichia coli isolated from cattle, Antimicrob. Agents Chemother. 44 (2000) 2858-2860.

[33] Cogan T.A., Humphrey T.J., The rise and fall of Salmonella Enteritidis in the UK, J. Appl. Microbiol. 94 (2003) 114S-119S.

[34] Cowden J.M., O’Mahony M., Bartlett C.L., Rana B., Smyth B., Lynch D., Tillett H., Ward L., Roberts D., Gilbert R.J., A national outbreak of Salmonella Typhimurium DT 124 caused by contaminated salami sticks, Epidemiol. Infect. 103 (1989) 219-225.

[35] Coyle E.F., Palmer S.R., Ribeiro C.D., Jones H.I., Howard A.J., Ward L., Rowe B., Salmonella Enteritidis phage type 4 infection: association with hen's eggs, Lancet 2 (1988) 1295-1297.

[36] Dalsgaard A., Forslund A., Serichantalergs O., Sandvang D., Distribution and content of class 1 integrons in different Vibrio cholerae O-serotype strains isolated in Thailand, Antimicrob. Agents Chemother. 44 (2000) 13151321.

[37] Davies R., Breslin M., Effects of vaccination and other preventive methods for Salmonella Enteritidis on commercial laying chicken farms, Vet. Rec. 153 (2003) 673-677.

[38] Davies R.H., Breslin M., Persistence of Salmonella Enteritidis phage type 4 in the environment and arthropod vectors on an empty free-range chicken farm, Environ. Microbiol. 5 (2003) 79-84.

[39] Davis M.A., Hancock D.D., Besser T.E., Rice D.H., Gay J.M., Gay C., Gearhart L., DiGiacomo R., Changes in antimicrobial resistance among Salmonella enterica serovar typhimurium isolates from humans and cattle in the Northwestern United States, 1982 1997, Emerg. Infect. Dis. 5 (1999) 802-806.

[40] Davis M.A., Hancock D.D., Besser T.E., Rice D.H., Gay J.M., Reply to Drs Angulo and Collignon, Emerg. Infect. Dis. 6 (2000) 437-438.

[41] Delarocque Astagneau E., Desenclos J.C., Bouvet P., Grimont P.A.D., Risk factors for the occurrence of sporadic Salmonella enterica serotype Enteritidis infections in children in France: a national case-control study, Epidemiol. Infect. 121 (1998) 561-567.

[42] Desenclos J.C., Bouvet P., Pierre V., Brisabois A., Fremy S., Lahellec C., Grimont F., Grimont P.A., Epidémiologie des infections à Salmonella : tendances récentes en France et en Europe, Bull. Soc. Fr. Microb. 11 (1996) 209.

[43] Doublet B., Lailler R., Meunier D., Brisabois A., Boyd D., Mulvey M.R., Chaslus-Dancla E., Cloeckaert A., Variant Salmonella genomic island 1 antibiotic resistance gene cluster in Salmonella enterica serovar Albany, Emerg. Infect. Dis. 9 (2003) 585-591.

[44] Doublet B., Weill F.X., Fabre L., ChaslusDancla E., Cloeckaert A., Variant Salmonella genomic island 1 antibiotic resistance gene cluster containing a novel 3'-N-aminoglycoside acetyltransferase gene cassette, aac(3)Id, in Salmonella enterica serovar newport, Antimicrob. Agents Chemother. 48 (2004) 3806-3812.

[45] Duchet Suchaux M., Lechopier P., Marly J., Bernardet P., Delaunay R., Pardon P., Quantification of experimental Salmonella Enteritidis carrier state in B13 leghorn chicks, Avian Dis. 39 (1995) 796.

[46] Duchet Suchaux M., Mompart F., Berthelot F., Beaumont C., Lechopier P., Pardon P., Differences in frequency, level, and duration of cecal carriage between four outbred chicken lines infected orally with Salmonella Enteritidis, Avian Dis. 41 (1997) 559-567.

[47] Dunne E.F., Fey P.D., Kludt P., Reporter R., Mostashari F., Shillam P., Wicklund J., Miller C., Holland B., Stamey K., Barrett T.J., Rasheed J.K., Tenover F.C., Ribot E.M., Angulo F.J., Emergence of domestically acquired ceftriaxone-resistant Salmonella infections associated with AmpC beta-lactamase, JAMA 284 (2000) 3151-3156.

[48] Edwards R.A., Olsen G.J., Maloy S.R., Comparative genomics of closely related Salmonellae, Trends Microbiol. 10 (2002) 94-99.

[49] Ekperigin H.E., Nagaraja K.V., Salmonella, Vet. Clin. North Am. Food Anim. Pract. 14 (1998) 17

[50] Fluit A.C., Schmitz F.J., Class 1 integrons, gene cassettes, mobility, and epidemiology, 
Eur. J. Clin. Microbiol. Infect. Dis. 18 (1999) 761-770.

[51] Friedman C.R., Malcolm G., Rigau-Perez J.G., Arambulo P. 3rd, Tauxe R.V., Public health risk from Salmonella-based rodenticides, Lancet 347 (1996) 1705-1706.

[52] Garber L., Smeltzer M., Fedorka-Cray P., Ladely S., Ferris K., Salmonella enterica serotype Enteritidis in table egg layer house environments and in mice in USA layer houses and associated risk factors, Avian Dis. 47 (2003) 134-142.

[53] Gast R.K., Holt P.S., Persistence of Salmonella Enteritidis from one day of age until maturity in experimentally infected layer chickens, Poult. Sci. 77 (1998) 1759-1762.

[54] Gast R.K., Holt P.S., Experimental horizontal transmission of Salmonella Enteritidis strains (phage types 4, 8, and 13a) in chicks, Avian Dis. 43 (1999) 774-778.

[55] Gast R.K., Guard-Petter J., Holt P.S., Effect of prior serial in vivo passage on the frequency of Salmonella Enteritidis contamination in eggs from experimentally infected laying hens, Avian Dis. 47 (2003) 633-639.

[56] Giraud A., Radman M., Matic I., Taddei F., The rise and fall of mutator bacteria, Curr. Opin. Microbiol. 4 (2001) 582-585.

[57] Giraud E., Cloeckaert A., Kerboeuf D., ChaslusDancla E., Evidence for active efflux as the primary mechanism of resistance to ciprofloxacin in Salmonella enterica serovar Typhimurium, Antimicrob. Agents Chemother. 44 (2000) 1223-1228.

[58] Giraud E., Cloeckaert A., Baucheron S., Mouline C., Chaslus-Dancla E., Fitness cost of fluoroquinolone resistance in Salmonella enterica serovar Typhimurium, J. Med. Microbiol. 52 (2003) 697-703.

[59] Glynn M.K., Bopp C., Dewitt W., Dabney P., Mokhtar M., Angulo F.J., Emergence of multidrug-resistant Salmonella enterica serotype Typhimurium DT104 infections in the United States, N. Engl. J. Med. 338 (1998) 1333-1338.

[60] Groisman E.A., Ochman H., Pathogenicity islands: bacterial evolution in quantum leaps, Cell 87 (1996) 791-794.

[61] Guard Petter J., Henzler D.J., Rahman M.M., Carlson R.W., On-farm monitoring of mouseinvasive Salmonella enterica serovar Enteritidis and a model for its association with the production of contaminated eggs, Appl. Environ. Microbiol. 63 (1997) 1588-1593.

[62] Gupta S., Maiden M.C., Feavers I.M., Nee S., May R.M., Anderson R.M., The maintenance of strain structure in populations of recombin- ing infectious agents, Nat. Med. 2 (1996) 437 442.

[63] Hacker J., Blumoehler G., Muhldorfer I., Tschape H., Pathogenicity islands of virulent bacteria: structure, function and impact on microbial evolution, Mol. Microbiol. 23 (1997) 1089.

[64] Hall R.M., Collis C.M., Mobile gene cassettes and integrons: capture and spread of genes by site-specific recombination, Mol. Microbiol. 15 (1995) 593-600.

[65] Harrison C., Quigley C., Kaczmarski E., Devlin E., An outbreak of gastro-intestinal illness caused by eggs containing Salmonella-Enteritidis phage Type-4, J. Infect. 24 (1992) 207210.

[66] Heisig P., High-level fluoroquinolone resistance in a Salmonella Typhimurium isolate due to alterations in both gyrA and gyrB genes, $\mathrm{J}$. Antimicrob. Chemother. 32 (1993) 367-377.

[67] Heisig P., Kratz B., Halle E., Graser Y., Altwegg M., Rabsch W., Faber J.P., Identification of DNA gyrase A mutations in ciprofloxacinresistant isolates of Salmonella Typhimurium from men and cattle in Germany, Microb. Drug Resist. 1 (1995) 211-218.

[68] Helmuth R., Schroeter A., Molecular typing methods for $S$. Enteritidis, Int. J. Food Microbiol. 21 (1994) 69.

[69] Henken A.M., Frankena K., Goelema J.O., Graat E.A., Noordhuizen J.P., Multivariate epidemiological approach to salmonellosis in broiler breeder flocks, Poult. Sci. 71 (1992) 838-843.

[70] Hensel M., Evolution of pathogenicity islands of Salmonella enterica, Int. J. Med. Microbiol. 294 (2004) 95-102.

[71] Henzler D.J., Opitz H.M., The role of mice in the epizootiology of Salmonella Enteritidis infection on chicken layer farms, Avian Dis. 36 (1992) 625-631.

[72] Hickman-Brenner F.W., Stubbs A.D., Farmer J.J. 3rd, Phage typing of Salmonella Enteritidis in the United States, J. Clin. Microbiol. 29 (1991) 2817-2823.

[73] Hinton M., Bale J.A., Is Salmonella Enteritidis PT4 a super bug, Food Res. Intern. 27 (1994) 233.

[74] Hogue A., White P., Guardpetter J., Schlosser W., Gast R., Ebel E., Farrar J., Gomez T., Madden J., Madison M., Mcnamara A.M., Morales R., Parham D., Sparling P., Sutherlin W., Swerdlow D., Epidemiology and control of egg-associated Salmonella Enteritidis in the United States of America, Rev. Sci. Tech. Off. Int. Epizoot. 16 (1997) 542-553. 
[75] Holt P.S., Molting and Salmonella enterica serovar Enteritidis infection: the problem and some solutions, Poult. Sci. 82 (2003) 10081010.

[76] Hsueh P.R., Ciprofloxacin-resistant Salmonella enterica Typhimurium and Choleraesuis from Pigs to Humans, Taiwan, Emerg. Infect. Dis. 10 (2004) 60-68.

[77] Hu J.X., Bumstead N., Barrow P., Sebastiani G., Olien L., Morgan K., Malo D., Resistance to salmonellosis in the chicken is linked to NRAMP1 and TNC, Genome Res. 7 (1997) 693-704.

[78] Humbert F., Les salmonelloses aviaires, Bull. Soc. Vét. Prat. France 78 (1994) 321.

[79] Humphrey T.J., Contamination of egg shell and contents with Salmonella Enteritidis: a review, Int. J. Food Microbiol. 21 (1994) 3140.

[80] Kim E., Aoki T., Sequence analysis of the florfenicol resistance gene encoded in the transferable R-plasmid of a fish pathogen, Pasteurella piscicida, Microbiol. Immunol. 40 (1996) 665-669.

[81] Kim E.H., Aoki T., The transposon-like structure of IS26-tetracycline, and kanamycin resistance determinant derived from transferable R plasmid of fish pathogen, Pasteurella piscicida, Microbiol. Immunol. 38 (1994) 31-38.

[82] Kingsley R.A., Baumler A.J., Host adaptation and the emergence of infectious disease: the Salmonella paradigm, Mol. Microbiol. 36 (2000) 1006-1014.

[83] Kobryn K., Chaconas G., The circle is broken: telomere resolution in linear replicons, Curr. Opin. Microbiol. 4 (2001) 558-564.

[84] Lacroix F.J.C., Cloeckaert A., Grepinet O., Pinault C., Popoff M.Y., Waxin H., Pardon P., Salmonella Typhimurium acrb-like gene: identification and role in resistance to biliary salts and detergents and in murine infection, FEMS Microbiol. Lett. 135 (1996) 161-167.

[85] Lawson A.J., Desai M., O’Brien S.J., Davies R.H., Ward L.R., Threlfall E.J., Molecular characterisation of an outbreak strain of multiresistant Salmonella enterica serovar Typhimurium DT104 in the UK, Clin. Microbiol. Infect. 10 (2004) 143-147.

[86] Liebana E., Garcia-Migura L., Clouting C., Clifton-Hadley F.A., Breslin M., Davies R.H., Molecular fingerprinting evidence of the contribution of wildlife vectors in the maintenance of Salmonella Enteritidis infection in layer farms, J. Appl. Microbiol. 94 (2003) 1024-1029.

[87] Ling J.M., Chan E.W., Lam A.W., Cheng A.F., Mutations in topoisomerase genes of fluoroquinolone-resistant Salmonellae in Hong Kong, Antimicrob. Agents Chemother. 47 (2003) 3567-3573.

[88] Lister S.A., Salmonella Enteritidis infection in broilers and broiler breeders, Vet. Rec. 123 (1988) 350.

[89] Lomovskaya O., Warren M.S., Lee A., Galazzo J., Fronko R., Lee M., Blais J., Cho D., Chamberland S., Renau T., Leger R., Hecker S., Watkins W., Hoshino K., Ishida H., Lee V.J., Identification and characterization of inhibitors of multidrug resistance efflux pumps in Pseudomonas aeruginosa: novel agents for combination therapy, Antimicrob. Agents Chemother. 45 (2001) 105-116.

[90] Low J.C., Angus M., Hopkins G., Munro D., Rankin S.C., Antimicrobial resistance of Salmonella enterica Typhimurium DT104 isolates and investigation of strains with transferable apramycin resistance, Epidemiol. Infect. 118 (1997) 97-103.

[91] Lu S., Killoran P.B., Riley L.W., Association of Salmonella enterica serovar Enteritidis yafD with resistance to chicken egg albumen, Infect. Immun. 71 (2003) 6734-6741.

[92] Majtanova L., Occurrence of Salmonella enterica serotype Enteritidis phage types in the Slovak Republic, Eur. J. Epidemiol. 13 (1997) 243-245.

[93] Marimon J.M., Perez-Trallero E., Gomariz M., Rodriguez-Andres C., Lopez-Lopategui C., Salmonella enteric infections in Gipuzkoa, Spain, 1983-2000, Euro Surveill. 8 (2003) 50-54.

[94] Markogiannakis A., Tassios P.T., Lambiri M., Ward L.R., Kourea-Kremastinou J., Legakis N.J., Vatopoulos A.C., Multiple clones within multidrug-resistant Salmonella enterica serotype Typhimurium phage type DT104. The Greek Nontyphoidal Salmonella Study Group, J. Clin. Microbiol. 38 (2000) 1269-1271.

[95] Mead P.S., Slutsker L., Dietz V., McCaig L.F., Bresee J.S., Shapiro C., Griffin P.M., Tauxe R.V., Food-related illness and death in the United States, Emerg. Infect. Dis. 5 (1999) 607-625.

[96] Methner U., Barrow P.A., Berndt A., Steinbach G., Combination of vaccination and competitive exclusion to prevent Salmonella colonization in chickens: experimental studies, Int. J. Food Microbiol. 49 (1999) 35. 
[97] Meunier D., Boyd D., Mulvey M.R., Baucheron S., Mammina C., Nastasi A., Chaslus-Dancla E., Cloeckaert A., Salmonella enterica serotype Typhimurium DT 104 antibiotic resistance genomic island I in serotype paratyphi B, Emerg. Infect. Dis. 8 (2002) 430-433.

[98] Mira A., Klasson L., Andersson S.G., Microbial genome evolution: sources of variability, Curr. Opin. Microbiol. 5 (2002) 506512 .

[99] Miriagou V., Filip R., Coman G., Tzouvelekis L.S., Expanded-spectrum cephalosporinresistant Salmonella strains in Romania, J. Clin. Microbiol. 40 (2002) 4334-4336.

[100] Mirold S., Rabsch W., Rohde M., Stender S., Tschape H., Russmann H., Igwe E., Hardt W.D., Isolation of a temperate bacteriophage encoding the type III effector protein sope from an epidemic Salmonella Typhimurium strain, Proc. Natl. Acad. Sci. USA 96 (1999) 9845-9850.

[101] Mulvey M.R., Soule G., Boyd D., Demczuk W., Ahmed R., Characterization of the first extended-spectrum beta-lactamase-producing Salmonella isolate identified in Canada, J. Clin. Microbiol. 41 (2003) 460-462.

[102] Nakaya H., Yasuhara A., Yoshimura K., Oshihoi Y., Izumiya H., Watanabe H., Lifethreatening infantile diarrhea from fluoroquinolone-resistant Salmonella enterica Typhimurium with mutations in both gyrA and parC, Emerg. Infect. Dis. 9 (2003) 255257.

[103] Navarro F., Perez-Trallero E., Marimon J.M., Aliaga R., Gomariz M., Mirelis B., CMY-2-producing Salmonella enterica, Klebsiella pneumoniae, Klebsiella oxytoca, Proteus mirabilis and Escherichia coli strains isolated in Spain (October 1999December 2000), J. Antimicrob. Chemother. 48 (2001) 383-389.

[104] Nunes I.A., Helmuth R., Schroeter A., Mead G.C., Santos M.A., Solari C.A., Silva O.R., Ferreira A.J., Phage typing of Salmonella Enteritidis from different sources in Brazil, J. Food Prot. 66 (2003) 324-327.

[105] Nygard K., De Jong B., Guerin P.J., Andersson Y., Olsson A., Giesecke J., Emergence of new Salmonella Enteritidis phage types in Europe? Surveillance of infections in returning travellers, BMC Med. 2 (2004) 32.

[106] O'Brien S.J., de Valk H., Salmonella - "old" organism, continued challenges! Euro Surveill. 8 (2003) 29-31.

[107] O’Brien S.J., de Valk H., Gillespie I., Charlett A., Adak B., Threlfall J., Ward L., National case-control study of Salmonella Enteritidis
Phage Type 14b infection in England and Wales implicates eggs used in the catering trade, eurosurveillance weekly 8 (2004) 19/02, http://www.eurosurveillance.org/ew/2004/ 040219-asp.

[108] O’Brien T.F., Emergence, spread, and environmental effect of antimicrobial resistance: how use of an antimicrobial anywhere can increase resistance to any antimicrobial anywhere else, Clin. Infect. Dis. 34 (2002) S78S84.

[109] Ochman H., Jones I.B., Evolutionary dynamics of full genome content in Escherichia coli, EMBO J. 19 (2000) 6637-6643.

[110] Ochman H., Lawrence J.G., Groisman E.A., Lateral gene transfer and the nature of bacterial innovation, Nature 405 (2000) 299304.

[111] Olsen S.J., DeBess E.E., McGivern T.E., Marano N., Eby T., Mauvais S., Balan V.K., Zirnstein G., Cieslak P.R., Angulo F.J., A nosocomial outbreak of fluoroquinoloneresistant Salmonella infection, N. Engl. J. Med. 344 (2001) 1572-1579.

[112] Parsons Y., Hall R.M., Stokes H.W., A new trimethoprim resistance gene, dhfrX, in the In7 integron of plasmid pDGO100, Antimicrob. Agents Chemother. 35 (1991) 24362439.

[113] Partridge S.R., Hall R.M., In34, a complex In 5 family class 1 integron containing orf513 and dfrA10, Antimicrob. Agents Chemother. 47 (2003) 342-349.

[114] Partridge S.R., Brown H.J., Stokes H.W., Hall R.M., Transposons Tn1696 and Tn21 and their integrons In4 and In 2 have independent origins, Antimicrob. Agents Chemother. 45 (2001) 1263-1270.

[115] Partridge S.R., Recchia G.D., Stokes H.W. Hall R.M., Family of class 1 integrons related to In4 from Tn1696, Antimicrob. Agents Chemother. 45 (2001) 3014-3020.

[116] Partridge S.R., Collis C.M., Hall R.M., Class 1 integron containing a new gene cassette, aadA10, associated with Tn1404 from R151, Antimicrob. Agents Chemother. 46 (2002) 2400-2408.

[117] Paulsen I.T., Brown M.H., Skurray R.A., Proton-dependent multidrug efflux systems, Microbiol. Rev. 60 (1996) 575-608.

[118] Perna N.T., Plunkett G. 3rd, Burland V., Mau B., Glasner J.D., Rose D.J., Mayhew G.F., Evans P.S., Gregor J., Kirkpatrick H.A., Posfai G., Hackett J., Klink S., Boutin A., Shao Y., Miller L., Grotbeck E.J., Davis N.W., Lim A., Dimalanta E.T., Potamousis 
K.D., Apodaca J., Anantharaman T.S., Lin J., Yen G., Schwartz D.C., Welch R.A., Blattner F.R., Genome sequence of enterohaemorrhagic Escherichia coli O157:H7, Nature 409 (2001) 529-533.

[119] Piddock L.J., White D.G., Gensberg K., Pumbwe L., Griggs D.J., Evidence for an efflux pump mediating multiple antibiotic resistance in Salmonella enterica serovar Typhimurium, Antimicrob. Agents Chemother. 44 (2000) 3118-3121.

[120] Pitt T.L., Livermore D.M., Miller G., Vatopoulos A., Legakis N.J., Resistance mechanisms of multiresistant serotype 012 Pseudomonas aeruginosa isolated in Europe, J. Antimicrob. Chemother. 26 (1990) 319328.

[121] Poole K., Multidrug resistance in Gramnegative bacteria, Curr. Opin. Microbiol. 4 (2001) 500-508.

[122] Popoff M.Y., Bockemuhl J., Gheesling L.L., Supplement 2001 (No. 45) to the KauffmannWhite scheme, Res. Microbiol. 154 (2003) 173-174.

[123] Poppe C., Demczuk W., McFadden K., Johnson R.P., Virulence of Salmonella Enteritidis phagetypes 4, 8 and 13 and other Salmonella spp. for day-old chicks, hens and mice, Can. J. Vet. Res. 57 (1993) 281-287.

[124] Poppe C., Salmonella Enteritidis in Canada, Int. J. Food Microbiol. 21 (1994) 1.

[125] Poppe C., Smart N., Khakhria R., Johnson W., Spika J., Prescott J., Salmonella Typhimurium DT104: a virulent and drug-resistant pathogen, Can. Vet. J. 39 (1998) 559565.

[126] Rabsch W., Hargis B.M., Tsolis R.M., Kingsley R.A., Hinz K.H., Tschape H., Baumler A.J., Competitive exclusion of Salmonella Enteritidis by Salmonella Gallinarum in poultry, Emerg. Infect. Dis. 6 (2000) 443-448.

[127] Rabsch W., Tschape H., Baumler A.J., Nontyphoidal salmonellosis: emerging problems, Microbes Infect. 3 (2001) 237-247.

[128] Rankin S.C., Aceto H., Cassidy J., Holt J., Young S., Love B., Tewari D., Munro D.S., Benson C.E., Molecular characterization of cephalosporin-resistant Salmonella enterica serotype Newport isolates from animals in Pennsylvania, J. Clin. Microbiol. 40 (2002) 4679-4684.

[129] Riemann H., Kass P., Cliver D., Salmonella Enteritidis epidemic [letter; comment], Science 287 (2000) 1754-1755; discussion 1755-1756.
[130] Schnabel E.L., Jones A.L., Distribution of tetracycline resistance genes and transposons among phylloplane bacteria in Michigan apple orchards, Appl. Environ. Microbiol. 65 (1999) 4898-4907.

[131] Soto S.M., Ruiz J., Mendoza M.C., Vila J., In vitro fluoroquinolone-resistant mutants of Salmonella enterica serotype Enteritidis: analysis of mechanisms involved in resistance, Int. J. Antimicrob. Agents 22 (2003) 537-540.

[132] Spratt B.G., Hanage W.P., Feil E.J., The relative contributions of recombination and point mutation to the diversification of bacterial clones, Curr. Opin. Microbiol. 4(2001) 602-606.

[133] Stokes H.W., Tomaras C., Parsons Y., Hall R.M., The partial 3'-conserved segment duplications in the integrons In6 from $\mathrm{pSa}$ and In 7 from pDGO100 have a common origin, Plasmid 30 (1993) 39-50.

[134] Summers A.O., Generally overlooked fundamentals of bacterial genetics and ecology, Clin. Infect. Dis. 34 Suppl. 3 (2002) S85S92.

[135] Suzuki S., Pathogenicity of Salmonella Enteritidis in poultry, Int. J. Food Microbiol. 21 (1994) 89-105.

[136] Tamas I., Klasson L., Canback B., Naslund A.K., Eriksson A.S., Wernegreen J.J., Sandstrom J.P., Moran N.A., Andersson S.G., 50 million years of genomic stasis in endosymbiotic bacteria, Science 296 (2002) 23762379 .

[137] Tauxe R.V., Salmonella Enteritidis and Salmonella Typhimurium DT104: successful subtypes in the modern world, in: Scheld W.M., Craig W.A., Hughes J.M. (Eds.), Emerging Infections 3, ASM Press, Washington, DC, 1999, pp. 37-53.

[138] Threlfall E.J., Frost J.A., Ward L.R., Rowe B., Epidemic in cattle and humans of Salmonella Typhimurium DT 104 with chromosomally integrated multiple drug resistance, Vet. Rec. 134 (1994) 577.

[139] Threlfall E.J., Hampton M.D., Schofield S.L., Ward L.R., Frost J.A., Rowe B., Epidemiological application of differentiating multiresistant Salmonella Typhimurium DT104 by plasmid profile, Commun. Dis. Rep. Rev. 6 (1996) R155-R159.

[140] Threlfall E.J., Ridley A.M., Ward L.R., Rowe B., Assessment of health risk from Salmonella-based rodenticides, Lancet 348 (1996) 616-617. 
[141] Threlfall E.J., Epidemic Salmonella Typhimurium DT 104-a truly international multiresistant clone, J. Antimicrob. Chemother. 46 (2000) 7-10.

[142] Thungapathra M., Amita, Sinha K.K., Chaudhuri S.R., Garg P., Ramamurthy T., Nair G.B., Ghosh A., Occurrence of antibiotic resistance gene cassettes aac (6')-Ib, dfrA5, dfrA 12, and ere A2 in class I integrons in non-O1, non-O139 Vibrio cholerae strains in India, Antimicrob. Agents Chemother. 46 (2002) 2948-2955.

[143] Uzzau S., Brown D.J., Wallis T., Rubino S., Leori G., Bernard S., Casadesus J., Platt D.J., Olsen J.E., Host adapted serotypes of Salmonella enterica, Epidemiol. Infect. 125 (2000) 229-255.

[144] Van de Giessen A.W., Ament A.J.H.A., Notermans S.H.W., Intervention strategies for Salmonella Enteritidis in poultry flocks: a basic approach, Int. J. Food Microbiol. 21 (1994) 145-154.

[145] Van Pelt W., de Wit M.A., Wannet W.J., Ligtvoet E.J., Widdowson M.A., van Duynhoven Y.T., Laboratory surveillance of bacterial gastroenteric pathogens in The Netherlands, 1991-2001, Epidemiol. Infect. 130 (2003) 431-441.

[146] Varnam A.H., Evans M.G., Salmonella, Foodborne pathogens, an illustrated text, Wolfe publishing Ltd, 1993, p. 51.

[147] Wall P.G., Morgan D., Lamden K., Ryan M., Griffin M., Threlfall E.J., Ward L.R., Rowe B., A case control study of infection with an epidemic strain of multiresistant Salmonella Typhimurium DT104 in England and Wales, Commun. Dis. Rep. Rev. 4 (1994) R130R135.

[148] Ward L.R., de Sa J.D., Rowe B., A phagetyping scheme for Salmonella Enteritidis, Epidemiol. Infect. 99 (1987) 291-294.

[149] Ward L.R., Threlfall J., Smith H.R., O’Brien S.J., Salmonella Enteritidis epidemic, Science 287 (2000) 1753-1754; discussion $1755-1756$.

[150] Ward L.R., Threlfall J., Smith H.R., O’Brien S.J., Riemann H., Kass P., Cliver D., Bäumler A.J., Hargis B.M., Tsolis R.M., Salmonella
Enteritidis epidemic, Science 287 (2000) 1753-1754.

[151] White D.G., Zhao S., Sudler R., Ayers S., Friedman S., Chen S., McDermott P.F., McDermott S., Wagner D.D., Meng J., The isolation of antibiotic-resistant Salmonella from retail ground meats, N. Engl. J. Med. 345 (2001) 1147-1154.

[152] White P.L., Baker A.R., James W.O., Strategies to control Salmonella and Campylobacter in raw poultry products, Rev. Sci. Tech. 16 (1997) 525-541.

[153] Woodward M.J., Gettinby G., Breslin M.F., Corkish J.D., Houghton S., The efficacy of Salenvac, a Salmonella enterica subsp. enterica serotype Enteritidis iron-restricted bacterin vaccine, in laying chickens, Avian Pathol. 31 (2002) 383-392.

[154] Yan J.J., Ko W.C., Chiu C.H., Tsai S.H., Wu H.M., Wu J.J., Emergence of ceftriaxoneresistant Salmonella isolates and rapid spread of plasmid-encoded CMY-2-like cephalosporinase, Taiwan, Emerg. Infect. Dis. 9 (2003) 323-328.

[155] Zansky S., Wallace B., Schoonmaker-Bopp D., Smith P., Ramsey F., Painter J., Gupta A., Kalluri P., Noviello S., From the Centers for Disease Control and Prevention. Outbreak of multi-drug resistant Salmonella NewportUnited States, January-April 2002, JAMA 288 (2002) 951-953.

[156] Zhang S., Santos R.L., Tsolis R.M., Mirold S., Hardt W.D., Adams L.G., Baumler A.J., Phage mediated horizontal transfer of the sopE1 gene increases enteropathogenicity of Salmonella enterica serotype Typhimurium for calves, FEMS Microbiol. Lett. 217 (2002) 243-247.

[157] Zhao J., Aoki T., Nucleotide sequence analysis of the class $G$ tetracycline resistance determinant from Vibrio anguillarum, Microbiol. Immunol. 36 (1992) 1051-1060.

[158] Zhao S., White D.G., McDermott P.F., Friedman S., English L., Ayers S., Meng J., Maurer J.J., Holland R., Walker R.D., Identification and expression of cephamycinase bla(CMY) genes in Escherichia coli and Salmonella isolates from food animals and ground meat, Antimicrob. Agents Chemother. 45 (2001) 3647-3650. 